\title{
MECANISMO DE AÇÃO DAS VACINAS UTILIZADAS PARA A COVID-ı9 ATUALMENTE COMO USO EMERGENCIAL NO BRASIL
}

\author{
MECHANISM OF ACTION OF VACCINES USED FOR COVID-I9 CURRENTLY AS AN \\ EMERGENCY USE IN BRAZIL
}

\author{
Andresa Moura de Oliveira ${ }^{1}$ \\ Bárbara Giovana Rodrigues dos Santos ${ }^{2}$ \\ Kethellen Jade dos Reis Martins Gomes ${ }^{3}$ \\ Letícia Ketelly Soares da Rocha ${ }^{4}$ \\ Victoria Maria Alves Arruda ${ }^{5}$ \\ William Argolo Saliba ${ }^{6}$ \\ Arilton Januário Bacelar Júnior ${ }^{7}$ \\ Marina de Oliveira Paro ${ }^{8}$
}

RESUMO: Os primeiros relatos de contaminação pelo vírus da COVID-ı9 foram notificados em dezembro de 2019, na China. A identificação do vírus foi feita através de lavagem broncoalveolar onde observaram o sequenciamento genético do SARS-Cov-2. Após a Organização Mundial da Saúde (OMS) declarar como pandemia os casos do novo coronavírus, a vacina se tornou uma prioridade para conter a propagação do vírus. Diante dessa situação, vários laboratórios se dedicaram à produção da vacina no mundo todo como uma forma de monitorar a situação atual de pandemia causada pelo vírus SARS-CoV-2. Nos dias de hoje as vacinas desenvolvidas para a COVID-ı estão relacionadas à proteína presente na membrana do vírus, denominada proteína Spike (S). O objetivo da vacina é a imunização através da indução da fabricação de anticorpos contra a proteína Spike impedindo assim a entrada do vírus. Hoje no Brasil é realizada a aplicação de quatro vacinas, a AstraZeneca, CoronaVac, Pfizer e Janssen. A AstraZeneca, vacina produzida pela Oxford possui um mecanismo de imunização que se dá através de um vírus geneticamente modificado, no caso o adenovírus. A vacina CoronaVac possui cepas inativas que levam a

\footnotetext{
I Discente do curso Biomedicina da Faculdade Única de Ipatinga (FUNIP). 6 Período. Email: andresa_moura_mgcf@hotmail.com

2 Discente do curso Biomedicina da Faculdade Única de Ipatinga (FUNIP). 6 ${ }^{\circ}$ Período Email: barbaragiovana.17@hotmail.com

3 Discente do curso Biomedicina da Faculdade Única de Ipatinga (FUNIP). 6 Período. Email: kethellenjader@hotmail.com

4 Discente do curso Biomedicina da Faculdade Única de Ipatinga (FUNIP). 6 Período. Email: ketellyleticia46@gmail.com

5 Discente do curso Biomedicina da Faculdade Única de Ipatinga (FUNIP). 6 Período. Email: vicarrudar2244@outlook.com

${ }^{6}$ Docente da Faculdade Única de Ipatinga (FUNIP). Email: 800038r@unicaipatinga.com.br

7 Docente da Faculdade Única de Ipatinga (FUNIP).Email: dr.arilton@gmail.com

${ }^{8}$ Docente da Faculdade Única de Ipatinga (FUNIP).Email: biomedicina@unicaipatinga.com.br
} 
uma resposta imunitária contra o SARS-Cov-2. A Pfizer produzida pela BioNTech é uma vacina de RNA mensageiro sintético. A Janssen produzida pela Janssen-Cilag é uma de vetor viral não replicante no qual utiliza o adenovírus tipo 26 (Ad26). Os sites oficiais de comunicação disponibilizam artigos e notas com informações sobre as etapas de desenvolvimento de cada vacina e qual tecnologia é utilizada em cada uma das vacinas produzidas, meios foram utilizadas como base para o desenvolvimento deste artigo. As vacinas distribuídas para a população apresentaram-se seguras e eficientes contra o agravamento da doença.

Palavra-chave: Vacinas. AstraZeneca. CoronaVac. Pfizer. Janssen. Coronavírus, SARSCov-2.

ABSTRACT: The first reports of COVID-I9 virus contamination were reported in December 2019 in China. Virus identification was performed through bronchoalveolar lavage, where the genetic sequencing of SARS-Cov-2 was observed. After WHO declared cases of the new coronavirus as a pandemic, the vaccine became a priority to contain the spread of the virus. Faced with this situation, several laboratories have dedicated themselves to the production of the vaccine around the world as a way to monitor the current situation of a pandemic caused by the SARS-CoV-2 virus. Nowadays, as vaccines developed for a COVID-9, they are related to the protein present in the virus membrane, called protein Spike (S). The aim of the vaccine is immunization by inducing protein manufacture against the Spike protein, thus preventing the entry of the virus. Today in Brazil, four vaccines are applied, AstraZeneca, CoronaVac, Pfizer and Janssen. AstraZeneca, applied by Oxford, has an immunization mechanism that takes place through a genetically modified virus in this case or adenovirus. The CoronaVac vaccine has inactive strains that lead to an immune response against SARS-Cov-2. The Pfizer adapted by BioNTech is a synthetic messenger RNA vaccine. Janssen required by Janssen-Cilag is a non-replicating viral vector in which adenovirus type $26(\mathrm{Ad} 26)$ is used. The official communication websites provide articles and notes with information about the stages of development of each vaccine and which technology is used in each of the vaccines produced, were used as the basis for the development of this article. Vaccines distributed to a family for safety and efficiency against the worsening of the disease.

Keyword: Vaccines. AstraZeneca. CoronaVac. Pfizer. Janssen. Coronavirus. SARS-Cov-2.

\section{INTRODUÇÃO}

Foi declarado estado de pandemia pela Organização Mundial da Saúde (OMS), após o novo vírus SARS-CoV-2 ter se espalhado rapidamente para todo o mundo. Para o controle da situação emergencial a ação mais importante para conter a disseminação da doença é o desenvolvimento de uma vacina que apresenta uma boa eficácia e seja segura para a população, diante a situação em que o mundo se encontra vários grupos foram avançando 
com o auxílio de informação acumulada sobre o coronavírus. O tempo de desenvolvimento para uma vacina normalmente é prolongado, podendo chegar a 20 anos, o processo de desenvolvimento da vacina é submetido em 4 fases realizadas em voluntários onde é avaliado sua seguridade, a produção da vacina é iniciada com a identificação do antígeno até as fases de ensaio clínico e por fim a aprovação, registro e distribuição para o uso da população. Espera-se que com a vacina contra o COVID-ig se tenha uma resposta imune gerada contra o vírus SARS-CoV-2 (ALWIS et al., 2020; MINISTERIO DA SAUDE, 2020).

As vacinas fabricadas para COVID-19 estão associadas à proteína contida na membrana do vírus, denominada proteína Spike(S), no qual o vírus utiliza essa proteína para infectar a célula, se ligando a enzima conversora de angiotensina 2 (ECA-2), assim a vacina consegue induzir a produção de anticorpos contra a proteína Spike. No âmbito mundial em agosto de 2020 havia 23 vacinas que já se encontrava na fase III de testes, sendo que no Brasil estão comercializadas quatro que foram aprovadas para uso emergencial, sendo a vacina AstraZeneca, CoronaVac, Pfizer e Janssen (ALVES et al., 2020; MINISTÉRIO DA SAÚDE, 2020; LIMA et al., 2021; GUIMARÃES, 2020).

O presente trabalho tem como objetivo descrever os mecanismos de ação das vacinas utilizadas para COVID-ı9 de uso emergencial no Brasil.

\section{METODOLOGIA}

Foi realizado um levantamento bibliográfico de publicações científicas provenientes de periódicos on-line para compor a revisão de literatura. A busca dos materiais foi através dos seguintes descritores: Vacinas, AstraZeneca, CoronaVac, Pfizer, Janssen, Coronavírus e SARS-CoV-2. Com base no levantamento bibliográfico, foram selecionadas 26 publicações disponíveis nas plataformas Google Acadêmico e Public Medline (PUBMED) abordando justamente sobre o assunto, sendo os critérios de inclusão: idiomas inglês e português, período de publicação entre os anos de 2020 e 2021. Já os critérios de exclusão usados na seleção dos materiais científicos foram: trabalhos não científicos, artigos com barreira monetária ou com abordagem fora do tema escolhido. 


\section{DESENVOLVIMENTO}

\section{I Origem da covid-19 e estruturas do SARS-CoV-2}

Registros de dezembro de 2019 mostraram um grupo de pacientes com uma pneumonia de ascendência desconhecida, em Wuhan, na China dando início à nova doença, sendo nomeada pela Organização Mundial da Saúde (OMS) como coronavírus, causada pelo vírus SARS-CoV-2 pertencente à família Coronaviridae, do gênero Betacoronavírus, responsável por causar síndromes respiratórias agudas, além de complicações no trato respiratório (PASTRIAN-SOTO, 2020; MINISTÉRIO DA SAÚDE; SECRETARIA DE ATENÇÃO ESPECIALIZADA À SAÚdE; DEPARTAMENTO DE ATENÇÃO HOSPITALAR, URGÊNCIA E DOMICILIAR, 2020).

A identificação do vírus foi realizada em uma amostra de lavado broncoalveolar de um paciente com sintomas, onde foram observadas em um sequenciamento genético características similares à família do coronavírus. A cepa $\beta$-CoV foi identificada semelhante a uma outra síndrome respiratória derivada de morcegos, no qual foi associado sendo a principal forma de transmissão para humanos (PASTRIAN-SOTO, 2020; XIAOWEI et al., 2020).

A estrutura do vírus SARS-CoV-2 é composta de RNA de fita simples com polaridade positiva, sua partícula possui uma coroa solar, estrutura que deu origem ao seu nome coronavírus, o seu material genético é envolvido por um nucleocapsídeo $\mathrm{N}$, sua estrutura externa contém proteínas, sendo a proteína Spike (S), proteína de membrana (M) e de envelope (E), além de proteínas acessórias. O mecanismo de ação do vírus para invadir a célula do corpo humano é através do processo de endocitose, com o auxílio da proteína Spike localizada na sua estrutura externa, esta proteína é capaz de se ligar o receptor enzima conversora angiotensina 2 presente na célula hospedeira (PASTRIAN-SOTO, 2020; PEGADO, et al., 2020; TEGALLY, et al., 2020). 
Figura 1- Estrutura do vírus Sars-CoV-2.

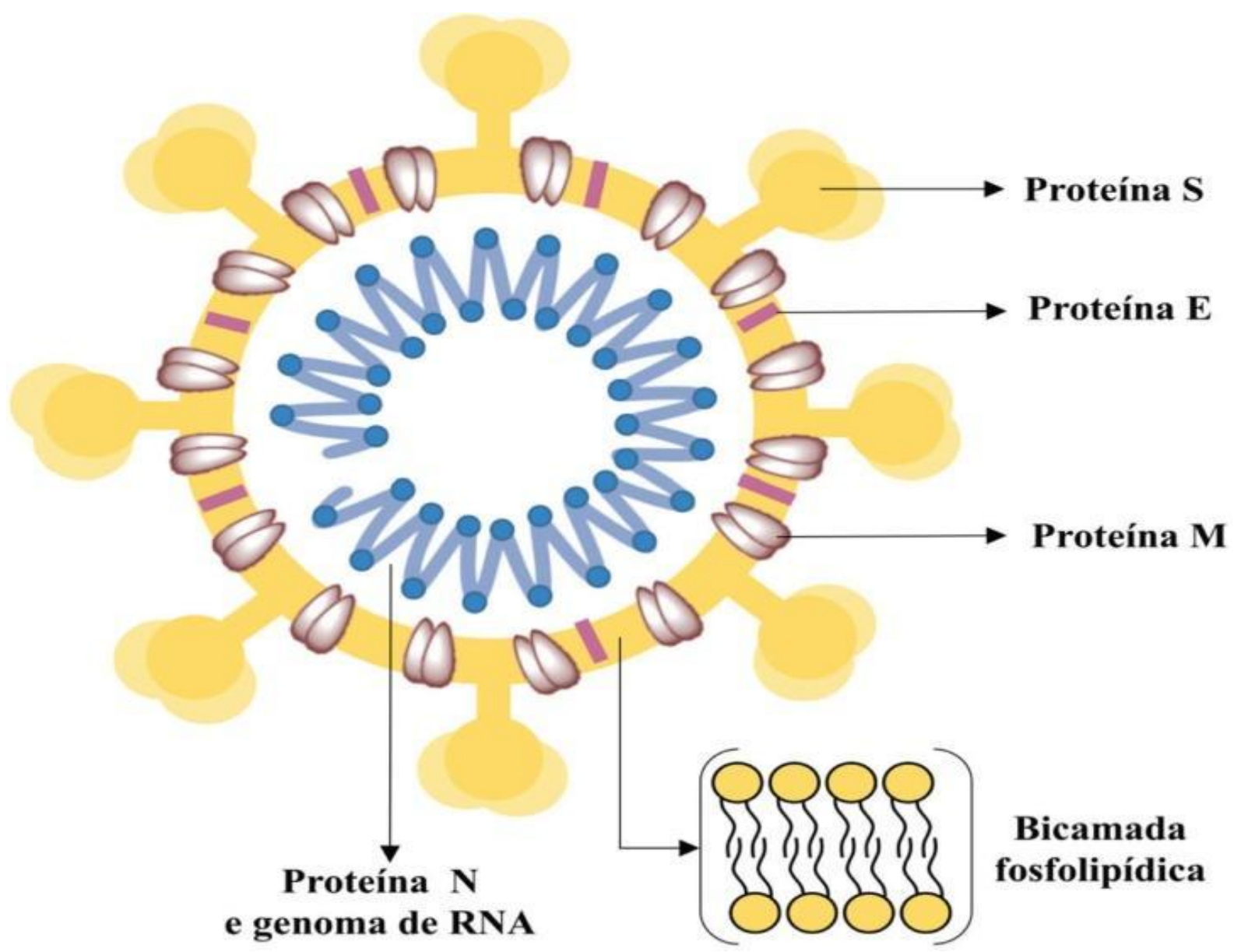

Fonte: A Química Dos Saneantes Em Tempos De Covid-ı:: Você Sabe Como Isso Funciona? (2020).

\subsection{Sintomas e transmissão}

Como se trata de uma nova infecção a sintomatologia da COVID-I9 se diferencia de acordo com cada paciente, sendo que $80 \%$ dos pacientes são assintomáticos ou oligossintomáticos e cerca de $20 \%$ apresentam alguma dificuldade respiratória. A tosse, febre, dor de garganta, vômitos, diarréia, dispnéia, coriza, ageusia, anosmia, falta de ar, entre outros são os sintomas mais relatados. A transmissão acontece através da aproximação, sendo de pessoa para pessoa, as principais formas de transmissão são tosse e espirro, toque em superfícies contaminadas e em outras pessoas e partículas salivares (MINISTÉRIO DA SAÚDE, 2020). 
A prevenção da COVID-ıg é focada principalmente no afastamento social, no qual se deve manter I metro de distância e fazer o uso correto de máscaras, cobrir nariz, boca e queixo. A realização da higienização das mãos utilizando água e sabão ou usar o álcool a $70 \%$, realizar a desinfecção de superfícies e não levar as mãos em locais como olhos, boca e nariz. No ano de 2020 o número de reprodução básica $\left(R_{0}\right)$ do SARS-CoV-2 era estimado com uma média de 3,I, o que significa que a cada I indivíduo infecta três a quatro pessoas. Após ações de intervenção esse número teve uma redução significativa, sendo até o presente desenvolvimento deste trabalho tem a estima de o,9I sendo abaixo de I é considerável que epidemia no país se apresenta estável (WORLD HEALTH ORGANIZATION, 202I; AKHAVAN, 2020; SITUATION REPORT FOR COVID-ı: Brazil, 202ı).

\subsection{Vacina como medida terapêutica em meio à pandemia}

Desde o descobrimento da vacina ao longo dos anos mostram-se como uma medida terapêutica segura e eficaz, mantendo doenças sob controle e até mesmo erradicando a sua circulação por completo, como no caso da varíola que foi erradicada mundialmente e o último registro de caso da doença foi em 1977, além de outras doenças que estão em processo de erradicação. O vírus influenza AHıNi causou um surto em 2009 e a vacina produzida foi responsável por controlar a doença, além do controle também das variantes do vírus (TOSCANO; KOSIM, 2003; LIMA et al., 202I).

Devido a atual pandemia causada pelo SARS-CoV-2 os esforços têm se voltado para a criação de uma vacina que seja eficaz contra o vírus, visto que ainda não há um método terapêutico específico para combater a COVID-19. Existem diversos tipos de vacinas com tecnologias diferentes, comumente são utilizadas vacinas baseadas em vírus e proteínas, porém há também vacinas de ácido nucleico (DNA e RNA), vetor viral, partículas semelhantes a vírus (VLP), entre outras (MINISTÉRIO DA SAÚDE, 2020; LIMA et al., 2021).

Vacinas de vírus, nesta vacina o vírus é introduzido no organismo, o qual irá induzir uma resposta imunológica. Existem vacinas de vírus atenuado e de inativado. As vacinas de vírus atenuado provocam a replicação do vírus, semelhante a uma infecção natural no organismo, assim induzindo uma resposta imune, possui eficácia em patologias como 
sarampo e febre amarela. As vacinas de vírus inativado necessitam de um intermediário como um microrganismo para induzir a resposta imune, nesta vacina o vírus é exposto à radiação, calor ou produtos químicos, impedindo assim sua replicação. Possui um processo simples e é seguro em longa data (MINISTÉRIO DA SAÚDE, 2020; LIMA et al., 2021; SOUTO, 2020).

Vacinas de proteínas, esta vacina consiste em produzir a proteína do vírus e introduzi-la no organismo humano. Existem vacinas de subunidades proteicas e de partículas semelhantes a vírus (VLP). As vacinas de subunidades consistem em utilizar pedaços purificados do vírus para estimular a resposta imune. As vacinas de VLP consistem em organizações proteicas semelhantes as sequências encontradas no vírus porém não possuem material genético, são capazes de provocar uma forte resposta imunológica (ALVES et al., 2020; MINISTÉRIO DA SAÚDE, 2020; SOUTO, 2020).

Vacinas de DNA E RNA, esta vacina utiliza fragmentos do material genético do vírus, no qual após a vacinação o organismo utilizará dados do DNA ou RNA para produção de antígenos indutores de resposta imune (MINISTÉRIO DA SAÚDE, 2020; LIMA et al., 202I).

Vacina de vetor viral, esta vacina utiliza um segundo vírus para transportar proteínas especificas capazes de estimular a resposta imune, um exemplo de vírus que possa ser utilizado é o adenovírus. Existem vacinas de vetor viral não replicante, ou seja, não irá se multiplicar, e há vacinas de vetor viral replicante, ou seja, irá se multiplicar (MINISTÉRIO DA SAÚDE, 2020; LIMA et al., 2021; SOUTO, 2020).

Embora as vacinas utilizadas possuam mecanismo de ação diferente, todas estão relacionadas à proteína contida na membrana do vírus, denominada proteína Spike (S). Para infectar a célula o vírus utiliza a sua proteína Spike fazendo com que se ligue a enzima conversora de angiotensina 2 (ECA-2). $\mathrm{O}$ intuito da vacina é induzir a produção de anticorpos contra a proteína Spike, contendo assim a entrada do vírus na célula hospedeira, porém pouco se sabe a respeito da capacidade de modificação do SARS-CoV-2, podendo tornar difícil o desenvolvimento de uma vacina que seja eficaz (ALVES et al., 2020; MINISTÉRIO DA SAÚDE, 2020; LIMA et al., 2021). 


\subsection{Produção das vacinas no Brasil}

Em um cenário padrão, levam-se em média até 20 anos para a produção de uma vacina, considerando todas suas fases de avaliação. Devido ao conhecimento já reunido sobre o SARS-CoV e MERS-CoV que foram responsáveis por epidemias passadas, o desenvolvimento foi acelerado para a produção da vacina de forma ágil e eficaz seguindo os protocolos (MINISTERIO DA SAUDE, 2020).

No Brasil para ocorrer a produção e validação de uma vacina necessita-se de algumas etapas, começando pela fase pré-clínica no qual busca identificar a estrutura do vírus, seu mecanismo de ação, bem como os receptores que utilizam, para assim iniciar um modelo que possa ser testado em células e em animais. Esta fase é de extrema importância para avaliar a eficiência da imunogenicidade, ou seja, avaliar a resposta imunológica do organismo (MINISTERIO DA SAUDE, 2020; PRADA; FERREIRA, 2020).

Após a aprovação da fase pré-clínica pelos órgãos do Sistema CEP/Conep (Comitês

de Ética em Pesquisa e Comissão Nacional de Ética em Pesquisa) e pela Agência Nacional de Vigilância Sanitária (ANVISA) a pesquisa avança para os ensaios clínicos que serão realizados em humanos e são subdivididos em quatro fases (MINISTÉRIO DA SAÚDE, 2020; PRADA; FERREIRA, 2020).

É testada em uma pequena parcela de indivíduos sadios a fase I da vacina avaliando sua segurança e sua capacidade inicial de resposta imunológica. $\mathrm{Na}$ fase II a vacina será testada em centenas de indivíduos com foco principal na avaliação da imunogenicidade. $\mathrm{Na}$ fase III a vacina será testada em milhares de indivíduos que possuem características que necessitam da indicação da vacina, buscando sempre reafirmar a segurança dos mesmos e possíveis efeitos adversos. Por último a fase IV que necessita da aprovação da ANVISA, esta é a fase de aprovação e comercialização, a vacina será avaliada a um longo prazo (MINISTÉRIO DA SAÚDE, 2020; PRADA; FERREIRA, 2020).

\subsection{Vacinas no Brasil}

Em agosto de 2020, havia no mundo 23 vacinas em fase de teste, onde apenas duas se encontravam na última etapa, a fase III. Além de mais 140 candidatas em fases anteriores. No Brasil estão sendo distribuídas quatro vacinas, que já foram testadas e aprovadas para 
uso emergencial, assim sendo as vacinas AstraZeneca, CoronaVac, Pfizer e Janssen (ALVES et al., 2020; GUIMARÃES, 2020).

Para haver uma distribuição e aplicabilidade de uma vacina contra o Sars-Cov-2, ao final de sua fase de testes ela deve evidenciar eficácia, segurança e efeitos colaterais mínimos, obter também aprovação pela Organização Mundial da Saúde (OMS) e da agência sanitária no país em que adotar a vacina, no Brasil, essa agência é a ANVISA. Uma vacina eficaz deve garantir uma memória imunológica extensa, vitalícia ou no mínimo uma ou mais décadas. Não deve trazer manifestações de enhancement, ou seja, não causar ou agravar a doença que deveria inibir (GUIMARÃES, 2020).

\subsection{Vacina AstraZeneca}

A vacina de Oxford conhecida de forma científica como AZD 1222/ChAdOxi nCoVıg/COVISHIELD e popularmente como AstraZeneca é uma vacina de vetor viral não replicante, sua administração é dividia em duas doses, aplicadas por via intramuscular. O mecanismo desta vacina para a imunização é através de um vírus geneticamente modificado, neste caso o adenovírus de chimpanzé. Nesta tecnologia o conteúdo genético do vírus é removido e substituído pelo material genético do coronavírus, assim que o gene é introduzido, o mesmo carrega o código responsável por codificar a proteína Spike do SARS$\mathrm{CoV}-2$, que é o encarregado de invadir as células. Fazendo com que após o indivíduo ser vacinado o adenovírus começará a produzir a proteína Spike, ensinando nosso sistema imune que todo antígeno com essa proteína deverá ser destruído. Portanto, posteriormente as duas doses da vacina recebidas, nosso organismo em contato com o SARS-CoV-2 irá identificá-lo rapidamente e o atacará (STEVANIM, 2020; PRADA; FERREIRA, 2020; CHAMAS, 2021; MINISTERIO DA SAUDE, 2020; SECRETARIA DO ESTADO DE MINAS GERAIS, 202I).

A pesquisa da fase III da vacina no Brasil inclui cerca de 10.300 voluntários com idade superior a 18 anos. No qual a convocação dessas pessoas começou em Junho de 2020, englobando cinco estados, sendo São Paulo, Rio de Janeiro, Bahia, Rio Grande do Norte e Rio Grande do Sul. A fase III consiste em administrar a vacina em 4 grupos, utilizando o método de 2 doses, com espaço de 4 a I2 semanas (MINISTERIO DA SAUDE, 2020). 
Em agosto de 2020 foi fornecido ao Ministério da Saúde pelo governo brasileiro um valor de R \$,9 bilhão para comercialização e produção da vacina. Em Setembro o Brasil fechou um acordo entre a AstraZeneca e a Fiocruz/BioManguinhos, no qual teve acesso a Ioo,4 milhões de doses e houve a transferência da tecnologia da vacina para a Fiocruz. Em Dezembro de 2020 houve a divulgação dos resultados parciais da fase III, onde foi concluída a eficácia da vacina na prevenção da COVID-ı. Essa análise foi baseada no estudo da fase III ocorrido no Brasil e no Reino Unido, onde utilizou ir.636 pessoas (MINISTERIO DA SAUDE, 2020; NINOMIYA, 202I).

Após a aprovação da AstraZeneca sua eficácia geral foi de 70\% (Entre 62\% a 90\%) onde a ANVISA pede 50\%, ou seja, apresentando resultado positivo, logo esperando assim que ajude no desafogamento da ocupação de hospitais no Brasil (SECRETARIA DO ESTADO DE MINAS GERAIS, 2021; NINOMIYA, 2021).

\subsection{Vacina CoronaVac}

A CoronaVac é uma vacina que contém cepas inativadas que causa uma resposta imunológica contra o SARS-CoV-2. Na realização da vacina foi utilizado a cepa do SARSCoV-2 (CNo2) onde foi ramificado em células de rim de macaco verde africano (células Vero Io-87 da OMS). Os fragmentos do novo coronavírus existentes na vacina são somente aqueles para reconhecimento do vírus e que não tem ação patológica. Ao término da fase de incubação, o vírus foi coletado, inativado com $\beta$-propiolactona, condensado, purificado e por fim adsorvido em hidróxido de alumínio. O complexo de hidróxido de alumínio foi então diluído em cloreto de sódio, solução salina tamponada com fosfato e água antes de ser esterilizado e filtrado para injeção, resultando no produto inativo. Sua administração é aplicada em duas doses, por via intramuscular (PRADA; FERREIRA, 2020; WU, et al. 2020; SECRETARIA DE ESTADO DE SAÚDE DE MINAS GERAIS, 2021).

Os dois primeiros ensaios clínicos foram feitos na China, mostrando uma boa imunogenicidade e livre de efeitos adversos, a vacina CoronaVac mostrou-se segura enquanto as fases I e II, após aplicação de duas doses as respostas imunológicas, produção de anticorpos neutralizantes se mostrou mais eficaz, a quantidade desses anticorpos podem diminuir significamente em pacientes mais idosos. A fase III do estudo clínico, 
randomizado e por placebo passou a ser conduzido no Brasil, pelo Centro de Pesquisas Clínicas do Instituto Central do Hospital das Clínicas da Faculdade de Medicina da Universidade de São Paulo iniciando em Julho de 2020 contando com 13.060 pessoas, englobando oito estados, sendo São Paulo, Distrito Federal, Rio de Janeiro, Minas Gerais, Rio Grande do Sul, Paraná, Mato Grosso e Mato Grosso do Sul (LIMA et al., 2021; PRADA; FERREIRA, 2020; MINISTERIO DA SAUDE, 2020).

Os resultados em relação à eficácia geral da vacina constatada pelo Instituto Butantan nos testes brasileiros foram no total de 50,39\% inicialmente pode aparentar baixo, mas quando detalhado podemos observar grande eficácia, pois, apresentou ıoo\% de eficácia em casos moderados e $78 \%$ de eficácia em casos graves do estudo, a ANVISA aprovou para o uso emergencial. Em Dezembro de 2020 ocorreu à chegada de milhão de doses da vacina CoronaVac no Instituto Butantan, logo em seguida começou a produção da vacina no Brasil (MINISTERIO DA SAUDE, 2020; ALMEIDA et al., 2021; SECRETARIA DE ESTADO DE SAÚDE DE MINAS GERAIS, 2021; NINOMIYA, 2021).

\subsection{Vacina Janssen}

A vacina Jassen Covid 19 possui como mecanismo de ação o vetor viral não replicante, no qual se utiliza um adenovírus tipo 26 (Ad26). Esta tecnologia utiliza o Ad26 para transferir um fragmento do DNA contido na proteína Spike do vírus SARS-CoV-2. Após a imunização o organismo se torna capaz de produzir a proteína Spike, ativando o sistema imune, podendo gerar uma resposta mais rápida e eficaz em contato com o SARS CoV-2. Sua aplicação é realizada em dose única de $0,5 \mathrm{ml}$. A vacina possui quatro meses e meio de validade acondicionados em temperatura de $2^{\circ} \mathrm{C}$ e $8^{\circ} \mathrm{C}$, após a abertura possui 6 horas de estabilidade (MINISTÉRIO DA SAÚDE, 2020; PRADA; FERREIRA, 2020; ANVISA, 202I).

Em agosto de 2020 a Anvisa aprovou o estudo da fase III no Brasil, no qual ocorreu em outubro e conteve 7.560 voluntários em ir estados brasileiros e 28 centros sendo São Paulo, Minas Gerais, Distrito Federal, Rio de Janeiro, Paraná, Bahia, Rio Grande do Norte, Santa Catarina, Rio Grande do Sul, Mato Grosso e Mato Grosso do Sul. O centro que estava à frente da pesquisa é o Centro Paulista de Investigação Clínica (Cepic). Em novembro de 
2020, a Anvisa obteve o pedido de submissão contínua da vacina COVID-19 AD26.COV2.S pelo desenvolvedor Janssen Cilag. Ainda em novembro de 2020 a documentação da fase I e II estava em análise pela Anvisa. No início de março de 202I houve o recebimento da documentação da fase III e no final de março a vacina foi aprovada para uso emergencial no Brasil (MINISTÉRIO DA SAÚDE, 2020; ANVISA, 2021).

Após a aprovação da Jassen sua eficácia geral foi de 66,9\% em casos leves e 76,7\% em casos graves posterior a I4 dias de imunização (ANVISA, 202I).

\subsection{Vacina Pfizer}

Pfizer ou BNTı62B2 é uma vacina com tecnologia de ácido nucleico que utiliza o RNA mensageiro (mRNA) modificado com nucleosídeo formulado em nanopartículas lipídicas (LNP) gerado através de células in vitro. As nanopartículas protegem o RNA de uma degradação, é uma tecnologia muito instável e segura. Após ser introduzida no organismo humano ela codifica a proteína S presente no SARS-CoV-2 que induz anticorpos neutralizantes e a resposta imune contra o vírus da COVID-19. A vacina induz as células do organismo humano a produzirem cópias idênticas dos RNAs virais que são identificadas através de uma das pontas do vírus. A Pfizer escolheu essa tecnologia do RNA por sua capacidade de produção acelerada, sua segurança e alta resposta imunológica (SECRETÁRIA DA SAÚDE DO ESTADO DO CEARÁ, 2021; WORLD HEALTH ORGANIZATION, 2020; YVETTE N. LAMB, 202I).

Os ensaios clínicos iniciais foram testados os dados de segurança e tolerabilidade, com cerca de 144 voluntários entre 18 a 55 anos receberam as duas doses entre 2I dias, tratase de um ensaio clínico randomizado controlado por placebo. Foram observados após 7 dias da aplicação da vacina efeitos leves (MINISTÉRIO DA SAÚDE. SECRETARIA DE CIÊNCIA, TECNOLOGIA, INOVAÇÃO E INSUMOS ESTRATÉGICOS EM SAÚDE. DEPARTAMENTO DE CIÊNCIA E TECNOLOGIA, 2020).

O estudo de fase II caracteriza por ensaio clínico randomizado cego para o observador e avalia a segurança e imunogenicidade da vacina em voluntários que se apresentam saudáveis com idade entre 18 e 55 anos, no esquema de aplicação de 2 doses da vacina, foram avaliados a produção de anticorpos neutralizantes (MINISTÉRIO DA SAÚDE. 
SECRETARIA DE CIÊNCIA, TECNOLOGIA, INOVAÇÃO E INSUMOS ESTRATÉGICOS EM SAÚDE. DEPARTAMENTO DE CIÊNCIA E TECNOLOGIA, 2020; ARAÚJO, et al., 2021).

A fase II/III teve início em 29 de abril de 2020 com cerca de 44 mil voluntários em diferentes países como Estados Unidos, Brasil, Turquia, Alemanha, Argentina e África do Sul em mais de 130 centros. A vacina BNTr62b2 foi eficaz neutralizando os vírus do SARSCoV-2 produzindo uma resposta imune humoral e adaptativa que juntas contribuem para a imunização contra a COVID-ı9 (MINISTÉRIO DA SAÚDE. SECRETARIA DE CIÊNCIA, TECNOLOGIA, INOVAÇÃO E INSUMOS ESTRATÉGICOS EM SAÚDE. DEPARTAMENTO DE CIÊNCIA E TECNOLOGIA, 2020; ARAÚJO, et al., 2021).

Em fevereiro de 2021, a ANVISA liberou o registro definitivo, que comprova a segurança, qualidade e eficácia da vacina. O esquema vacinal recomendado é com intervalo de 2I dias entre a primeira dose e a segunda com aplicação por via intramuscular. Os dados demonstraram que após a primeira dose a vacina já garante uma imunização parcial após cerca de I2 dias, mas são de grande importância que seja feita a imunização completa com as duas doses para que se possa garantir um potencial máximo da vacina. Sua eficácia global é de 95\% com a imunização completa das duas doses (LABORATÓRIOS PFIZER, 2021; MINISTÉRIO DA SAÚDE. SECRETARIA DE CIÊNCIA, TECNOLOGIA, INOVAÇÃO E INSUMOS ESTRATÉGICOS EM SAÚDE. DEPARTAMENTO DE CiÊNCIA E TECNOLOGIA, 2020; ARAÚJO, et al., 2021).

\section{1o Dados epidemiológicos da vacinação}

Até Outubro de 2021 os casos confirmados de COVID-19 no Brasil resultam em 2I.723.559 casos acumulados e 605.457 óbitos, a vacinação teve início em Janeiro de 2021 em São Paulo. Devido o cenário é de extrema importância uma vacina eficaz e segura, apresentando uma solução em grande potencial para o controle de casos e minimização de sintomas reduzindo a mortalidade (SECRETARIAS ESTADUAIS DE SAÚDE, 202I).

Depois de feita a distribuição da vacina em todo território brasileiro já foram aplicadas 259.842.070 doses, sendo na região Centro-Oeste: 19.607.834 doses, Norte: 17.483.477 
doses, Nordeste: 60.400.306, Sul: 39.905.184 e na região Sudeste: 122.445.269 doses já aplicadas como podemos ver representado no gráfico i abaixo (AGÊNCIA BRASIL; MINISTÉRIO DA SAUDE, 202I).

Gráfico I- Total de doses das vacinas aplicadas por regiões do Brasil referente á semana do dia 25 de outubro 2021.

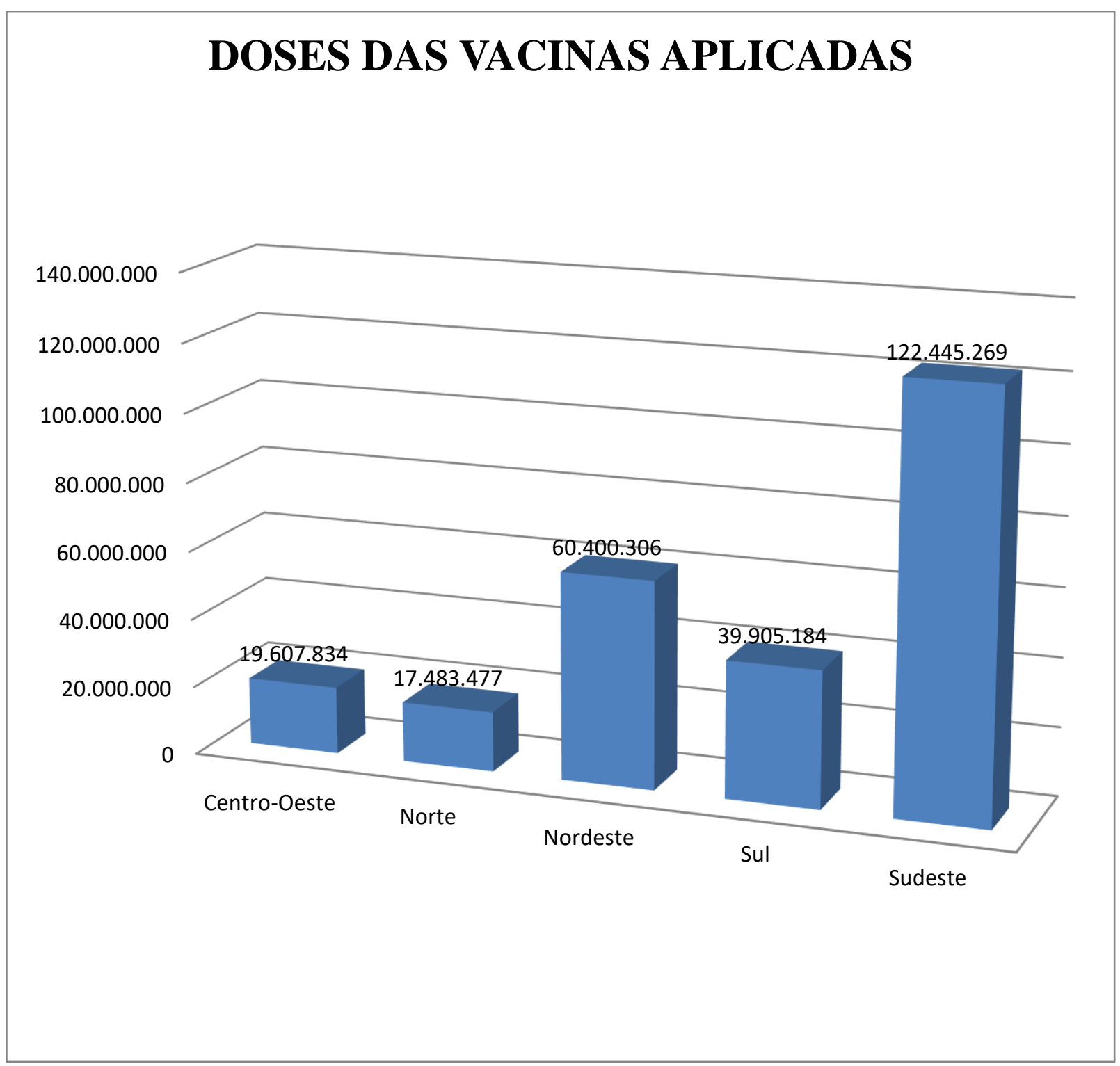

Fonte: AUTORES, 2021, com base nos dados do vacinômetro - SUS. Brasil, 202I. 
No gráfico 2 podemos observar a diminuição de número de óbitos após abril de 202I (SECRETARIAS ESTADUAIS DE SAÚDE, 2021).

Gráfico 2 - Número de óbitos por COVID-I9 referente ao ano de 202I até I de outubro.

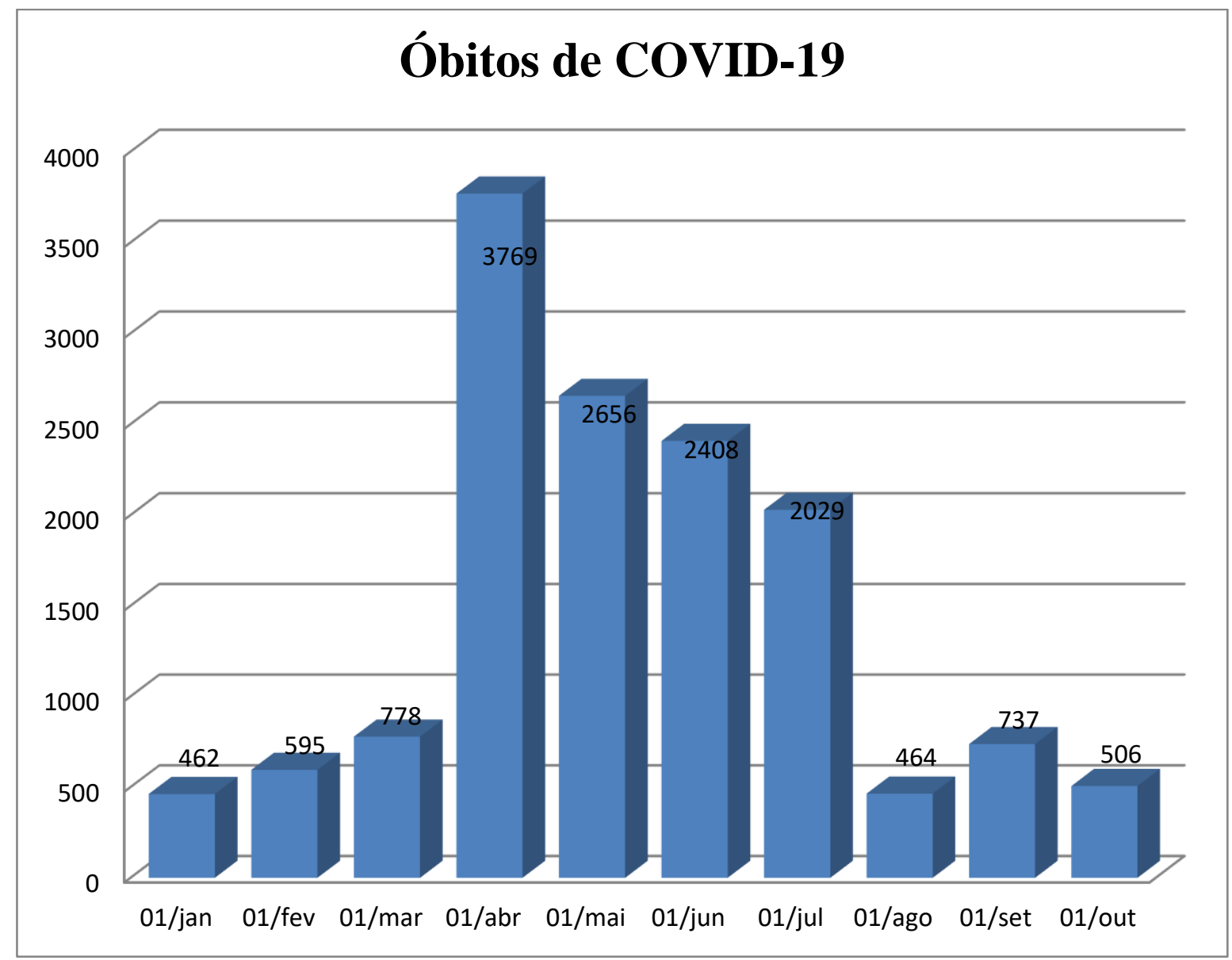

Fonte: AUTORES, 2021, com base nos dados do Painel Coronavírus - SECRETARIAS ESTADUAIS DE SAÚDE. Brasil, 2021.

\section{CONSIDERAÇÕES FINAIS}

Apesar da dificuldade de produção das vacinas, devido o estado atual que o mundo se encontra causado pelo vírus, às quatro vacinas que já estão sendo distribuídas no Brasil foram aprovadas pela ANVISA após ter passado por todas as fases de teste e mostrar eficaz contra os agravamentos causados pelo SARS-CoV-2, apresentados pelos resultados de todos os 3 testes clínicos, sendo o último realizado no Brasil. Apesar de ser uma vacina produzida 
em um tempo menor do que outras, sendo fabricada para o uso emergencial, é uma medida que vem apresentando melhora no controle dos casos em diversos países, de acordo com a distribuição da vacina na população ainda estão sendo estudadas e monitoradas os seus resultados e efeitos colaterais em relação a imunização contra o vírus por sua capacidade de mutação e reinfecção.

\section{REFERÊNCIAS BIBLIOGRÁFICAS}

AGÊNCIA BRASIL; MINISTÉRIO DA SAUDE. Vacinômetro - SUS. Painel Coronavírus. Ministério da Saúde. 202I.

AGÊNCIA NACIONAL DE VIGILÂNCIA SANITÁRIA - ANVISA. Anvisa aprova uso emergencial da vacina da Janssen. Ministério da Saúde. 202I.

AKHAVAN, A; AKHAVAN, D. Número Reprodutivo Da COVID-ı9 E O Relaxamento Do Distanciamento Social No Brasil. Revista Científica Multidisciplinar Núcleo do Conhecimento. 2020. v. 07, p. 129-137.

ARAÚJO, C; CAIXETA, L; COURY, B; CYRINO, L; FERNANDES, S; FIGUEIREDO, B; NETO, A; PERES, M; QUEIROZ, J; SOUSA, K; SOUSA, L; SOUSA, L. Vacinas de mRNA contra a Covid-19: aberta uma nova janela no campo da imunologia. 2021. Patos de Minas.

ALMEIDA, S; OLIVEIRA, D; FARIA, L; GODOY, M; OLIVEIRA, M; LOCH, M; PASCOTTO, S; MOREIRA, M.L; LUVIZOTTO, P.H; ABI-HABIB, Y. Uma Análise Crítica Das Vacinas Disponíveis Para SARS-CoV-2. Brazilian Journal of Health Review. 2021. v.4, n.2, p. $4537-4554$.

ALVES, P; ONO, L; FREITAS, N; SILVA, G; SOARES, C. VACINAS: História, Tecnologia E Desafios Para Terapia Contra O SARS-Cov-2. ULAKES J Med. 2020. p.125I4I. 
ALWIS, R; CHEN, S; GAN, E.S.; OOI, E.E. Impact Of Immune Enhancement On Covid19 Polyclonal Hyperimmune Globulin Therapy And Vaccine Development. EBioMedicine. 2020.

CHAMAS, C. Inovação, propriedade intelectual e acesso a medicamentos e vacinas: o debate internacional na pandemia da COVID-19. Liinc em Revista. 2020. Rio de Janeiro. v. I6, n. 2 .

GUIMARÃES, R. Vacinas Anticovid: um Olhar da Saúde Coletiva. Ciência e Saúde Coletiva. 2020. p. $3579-3585$.

LIMA, M; ALMEIDA, R; FONSECA, F; GONÇALVES, C. A Química Dos Saneantes

Em Tempos De Covid-ı: Você Sabe Como Isso Funciona?. Quím. Nova. 2020. v.43. n.5 p.:668-678

LIMA, E; SATO, H; GIAMBERARDINO, H; ANDRADE, S; FARIA, S; GURGEL, R; MARTINS, M. Vacinas COVID-rg. Departamento Científico de Imunizações. Sociedade Brasileira de Pediatria. 202I. n. I2.

MINISTÉRIO DA SAÚDE. SECRETARIA DE CIÊNCIA, TECNOLOGIA, INOVAÇÃO E INSUMOS ESTRATÉGICOS EM SAÚDE. DEPARTAMENTO DE CIÊNCIA E TECNOLOGIA. Relatório Técnico - Monitoramento De Vacinas Em Desenvolvimento Contra SARS-Cov-2. 2020. Brasília: Ministério da Saúde.

MINISTÉRIO DA SAÚdE; SECRETARIA DE CIÊNCIA, TECNOLOGIA, INOVAÇÃO E INSUMOS ESTRATÉGICOS EM SAÚDE; DEPARTAMENTO DE GESTÃO E INCORPORAÇÃO DE TECNOLOGIAS E INOVAÇÃO EM SAÚDE. Vacina da Fiocruz [ChAdOx-I (Vacina COVID-19 recombinante)] e da Pfizer/Wyeth [BNTı62b2 (Vacina COVID-ı9)] para prevenção da COVID-ı. Brasília. 202ı. 
MINISTRO DA SAÚDE. Plano Nacional De Operacionalização Da Vacinação Contra A Covid-ı. Secretaria de Vigilância em Saúde. Departamento de Imunização e Doenças Transmissíveis. Coordenação-Geral do Programa Nacional de Imunizações. 202ı. Brasília. $6^{\circ}$ edição.

MINISTÉRIO DA SAÚDE; SECRETARIA DE ATENÇÃO ESPECIALIZADA À SAÚDE; DEPARTAMENTO DE ATENÇÃO HOSPITALAR, URGÊNCIA E DOMICILIAR. Protocolo de Tratamento do Novo Coronavírus (2019-nCoV). Brasília. Ministério da Saúde. 2020.

MINISTÉRIO DA SAÚdE. SECRETARIA DE CIÊNCIA, TECNOLOGIA, INOVAÇÃO E INSUMOS ESTRATÉGICOS EM SAÚDE. DEPARTAMENTO DE CIÊNCIA E TECNOLOGIA. Relatório Técnico - Monitoramento De Vacinas Em Desenvolvimento Contra SARS-Cov-2. 2020. Brasília: Ministério da Saúde, 2020.

NINOMIYA, V. Vacinação covid-19: CoronaVac e AstraZeneca/Oxford. Secretaria do Estado de Minas Gerais. Minas Gerais, 2021.

PASTRIAN-SOTO, G. Bases Genéticas y Moleculares del COVID-ı9 (SARS-CoV2). Mecanismos de Patogénesis y de Respuesta Inmune. Int. J. Odontostomat., Temuco, v. I4, n. 3, p. 331-337.

PEGADO, R; SILVA, E; LIMA, I; GUALDI, L. Doença coronavírus 2019 (COVID-19) no Brasil: informações para fisioterapeutas. Rev. Assoc. Med. Bras.2020. vol.66, n.4. pp.498-50I.

PRADA, L; FERREIRA, J. COVID-r9, Diabetes e Vacinas. Revista Portuguesa de Diabetes. 2020.p. 131-138. 
SECRETARIAS ESTADUAIS DE SAÚDE. Painel Coronavírus. Coronavírus. Brasil, 2020 .

SECRETARIA DE ESTADO DE SAÚDE DE MINAS GERAIS. Coronavírus: Vacinômetro. SUS. 2021.

SITUATION REPORT FOR COVID-ı: Brazil. MRC Centre for Global Infectious Disease Analysis, Imperial College London. 2020.

SOUTO, X. Vacinas Contra a Covid-rg: Estado da arte. RECITAL - Revista de Educação, Ciência e Tecnologia de Almenara. 2020. v. 2, n. 2.

STEVANIM, L. Uma Vacina Para A Humanidade: Dá expectativa à realidade, os esforços para se chegar a uma vacina contra a COVID-ıg acessível à população. Fundação Oswaldo Cruz. RADIS. 2020. n. 216.

TEGALLY, H; WILKINSON, E; GIOVANETTI, M; IRANZADEH, S; FONSECA, V; GIANDHARI, J; DOOLABH, D; PILLAY, S; SAN, E; MSOMI, N; MLISANA, K; GottberG, A; WAlazA, S; Allam, M; ISMAil, A; MOHAle, T; Glass, A; ENGELBRECHT, S; ZYL, G; PREISER, W; PETRUCCIONE, F; SIGAL, A; HARDIE, D; MARAIS, G; HSIAO, M; KORSMAN, S; DAVIES, M; TYERS, L; MUDAU, I; YORK, D; MASLO, C; GOEDHALS, D; ABRAHAMS, S; LAGUDA-AKINGBA, O; ALISOLTANI-DEHKORDI, A; GODZIK, A; WIBMER, C; SEWELL, B; LOURENÇO, J; ALCANTARA, L.C; POND, S; WEAVER, S; MARTIN, D; LESSELLS, R.J; N BHIMAN, J; WILLIAMSON, C; OLIVEIRA, T. Emergence and rapid spread of a new severe acute respiratory syndrome-related coronavirus 2 (SARS-CoV-2) lineage with multiple spike mutations in South Africa. MedRxiv. The Preprint Server For Health Sciences. 2020 . 
TOSCANO, C; KOSIM, L. Cartilha De Vacinas: Para Quem Quer Mesmo Saber Das Coisas. Organização Pan-Americana da Saúde. 2003. p.40.

WU, Z; HU, Y; XU , M; CHEN, Z; YANG, W; JIANG, Z; LI, M; JIN, H; CUI, G; CHEN, P; WANG, L; ZHAO, G; DING, Y; ZHAO, Y; YIN, W. Safety, tolerability, and immunogenicity of an inactivated SARS-CoV-2 vaccine (CoronaVac) in healthy adults aged 6o years and older: a randomised, double-blind, placebo-controlled, phase $1 / 2$ clinical trial. The Lancet. 2021.

WORLD HEALTH ORGANIZATION. Coronavírus: Sintomas. 202I.

WORLD HEALTH ORGANIZATION. mRNA vaccines against COVID-rg: PfizerBioNTech COVID-ıg vaccine BNTr62b2. 2020.

YVETTE N, L. BNTr62b2 mRNA COVID-19 Vaccine: First Approval. Drugs. 81. p.495501. 2021.

XIAOWEI, L; LIESU, M; MANMAN, G; SHEMIN, L; YIZHAO, P. Molecular immune pathogenesis and diagnosis of COVID-19. Journal of Pharmaceutical Analysis io. p. I02-108. 2020. 